\title{
DESIGN MODIFICATIONS, FABRICATION AND TEST OF HFDB-03 RACETRACK MAGNET WOUND WITH PRE-REACTED Nb $\mathrm{NB}_{3}$ RU RTHERFORD CABLE
}

\author{
G. Ambrosio, N. Andreev, E. Barzi, S. Bhashyam, R. Carcagno, S. Feher, \\ L. Imbasciati, M. Lamm, Y. Pischalnikov, M. Tartaglia, J. Tompkins, \\ A.V. Zlobin \\ Fermi National Accelerator Laboratory \\ P.O. Box 500, Batavia, IL 60510
}

\begin{abstract}
A $10 \mathrm{~T}$ racetrack magnet (HFDB-03) wound with pre-reacted $\mathrm{Nb}_{3} \mathrm{Sn}$ Rutherford cable has been fabricated and tested at Fermilab. This magnet is the third one in a proof-ofprinciple series for the use of the React-and-Wind technology in common-coil dipole magnets for future accelerators. It consists of two flat racetrack coils (28 turns each) separated by $5 \mathrm{~mm}$. The maximum field on the coil, at the short sample limit of $16530 \mathrm{~A}$, is 10 tesla. The cable has 41 strands with $0.7 \mathrm{~mm}$ diameter and the minimum bend radius in the magnet ends is $90 \mathrm{~mm}$. The predecessor of this magnet (HFDB-02) reached $78 \%$ of the short sample limit at $7.7 \mathrm{~T}$. The mechanical design was improved and the fabrication procedure was slightly modified in order to address possible causes of limitation. In this paper we present the mechanical design and analysis of HFDB-03, the modifications to the fabrication procedure and the test results.
\end{abstract}

\section{INTRODUCTION}

A common coil dipole magnet using $\mathrm{Nb}_{3} \mathrm{Sn}$ and the React-and-Wind technology [1] is under development at Fermilab as part of a larger R\&D for future hadron colliders. Three racetrack magnets wound with pre-reacted conductor have been fabricated and tested in order to develop this technology. They were made of 41 -strand cable with $0.7 \mathrm{~mm}$ diameter and have a minimum bending-radius in the ends of $90 \mathrm{~mm}$. The strand diameter and the bending-radius are the same as in the common coil dipole. The coils have 28 turns and the maximum field on the coil is about 10 tesla. More details about the design may be found in [HFDB-01]. The second magnet of this series (HFDB-02) reached $78 \%$ of the short sample limit at 7.7 $\mathrm{T}$ [2]. Although far from the short sample this result was a record performance for this kind of magnets in the 10 tesla range. The analysis of the test results indicated some 
possible causes of the limited performance (bumps on the cable created during heat treatment, damages during assembly, uneven preload on magnet ends). It was decided to modify part of the design and of the fabrication process addressing these issues and to fabricate and test a new racetrack magnet.

\section{MODIFICATIONS TO THE MECHANICAL DESIGN AND FE ANALYSIS}

The design of HFDB-02 is shown in FIG 1. It consists of two racetrack-type coils, with 28 turns each, wound in a common coil configuration (i.e. the current flows in opposite directions in the two coils in order to reproduce the same field and force distribution as in a common-coil magnet). The coils are connected by a $\mathrm{Nb}$-Ti junction cable. The mechanical structure consists of G-10 inserts, bronze end shoes, stainless steel plates and pushers. The preload is provided by 57 25.4- $\mathrm{mm}$ (1") bolts (main bolts) mounted on 40-mm thick plates (main plates), 16 19-mm (3/4") bolts mounted on the end plates and $6412.7-\mathrm{mm}(1 / 2$ ") bolts mounted on the side pushers. More details on the design, fabrication and test results of HFDB-02 can be found in $[2,3]$. Test results showed that the magnet performance was limited to about $78 \%$ of the predicted short sample current. Some of the possible reasons leading to premature quench were suspected to be local damage to the coil during reaction inside the spool, poor alignment of the end shoes leading to inadequate end preloads and damage to the outermost turns during coil assembly. The first concern was addressed by modifying the winding procedure of the cable on the reaction spool. A gap was left between the innermost turn of the coil and the spool, in order to accommodate a thermal expansion of the spool larger than that of the cable. Before proceeding with design modifications it was decided to perform a two-dimensional finite element analysis of a completely unrestrained coil to fully understand the mechanics of the coil under the action of Lorentz forces.

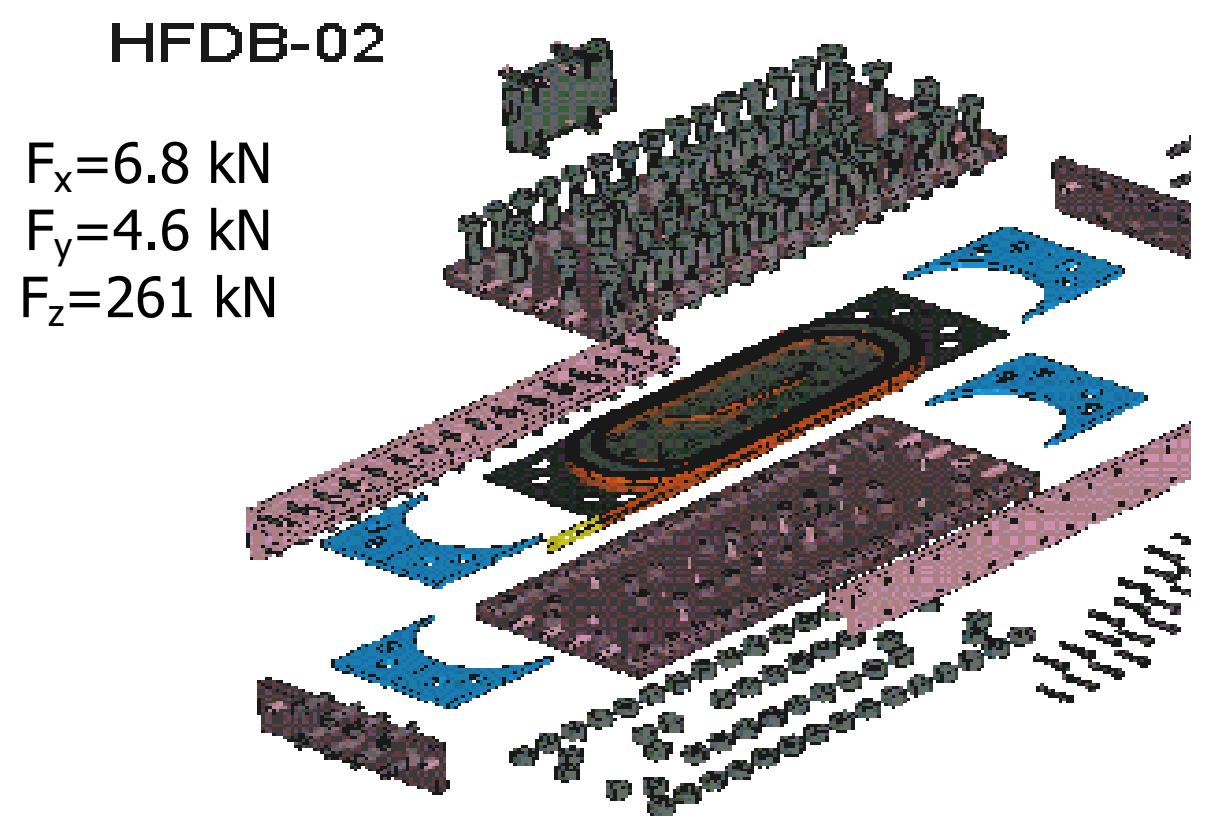

FIGURE 1. HFDB-02 mechanical structure and Lorentz forces at $12 \mathrm{kA}$ on a quadrant of a coil (see FIG. 2 for axis orientation). 

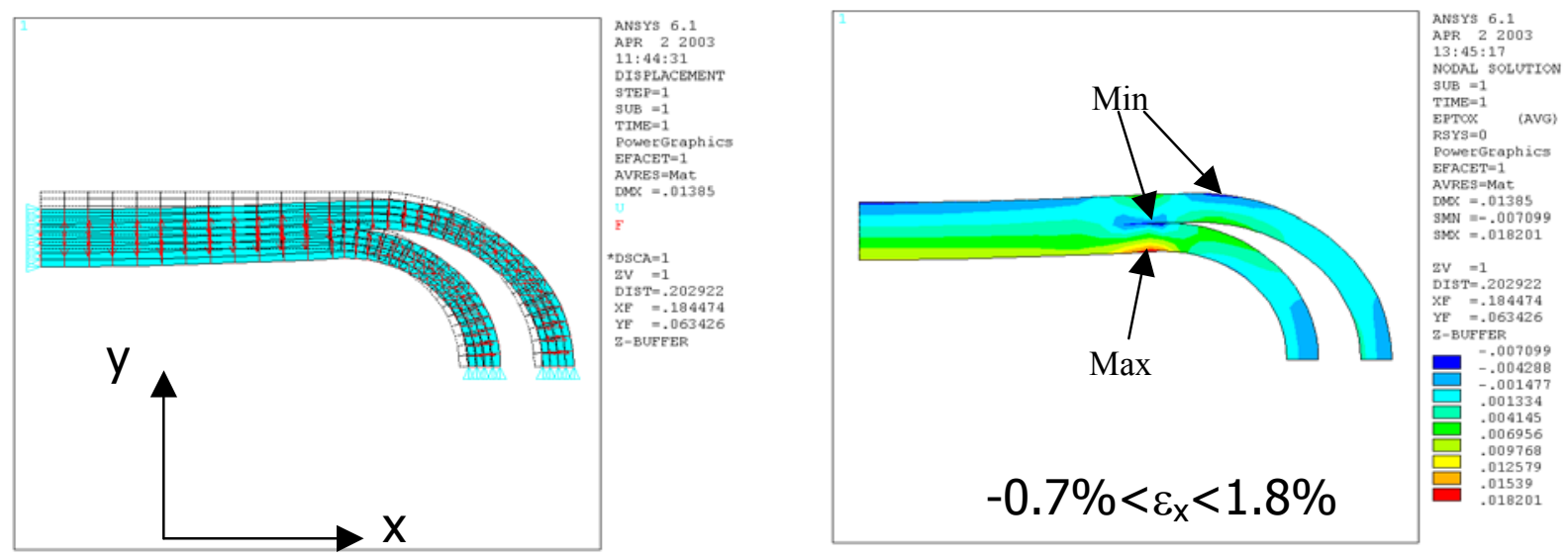

FIGURE 2. Unrestrained coil mechanics: deformation and strain in x-direction at $17 \mathrm{kA}$.

The finite element model and the coil deformations are shown in FIG 2. As it can be seen, the resultant forces in the ends tend to stretch and to bend the coil in the transition region causing high strains. This shows the need to have an adequate end preload such that the coil remains under compression, or moderate tension, even under the action of peak Lorentz forces.

The main drawback of the mechanical design of HFDB-02 was that a single surface of the end plate had to apply preload to all four end-saddles as shown in FIG. 1. The preload distribution could be quite non-uniform depending on the degree of relative misalignment between the end-saddles during assembly.

This concern was first addressed by introducing a slot in the end-saddles and locking them together using precision keys (FIG. 3). A small clearance of about 100 microns was added between the keys and the slot to allow for a small "opening" of end-saddle tips due to coil spring back after winding. The second modification enabled direct application of the preload on each end-saddle by bullets threaded into the end plate (FIG. 5).

A thorough 2D finite element analysis was performed to validate the design changes as well as to optimize the preloads that were to be applied during the first thermal cycle of testing. The goal was to achieve, in the first test, the minimum acceptable pre-stress at cold in order to decrease the risk of excessive local stress at room temperature (concern raised by the degradation in the outermost turns of HFDB-02). A higher pre-stress will be applied in a second test after the analysis of the results of the first one.
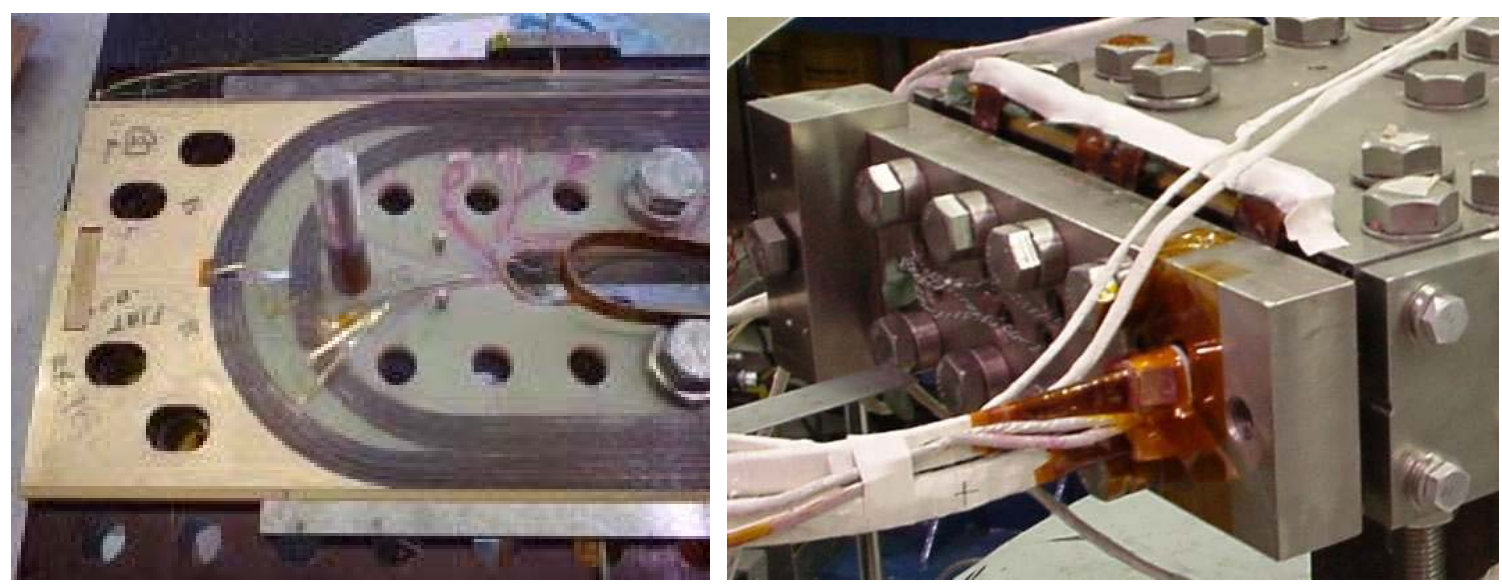

FIGURE 3. End saddles locked together by keys (LEFT), end loading using bullets (RIGHT) 
TABLE 1. Material properties used in the finite element models

\begin{tabular}{|c|c|c|c|c|}
\hline Component & Material & $\begin{array}{c}\text { Modulus (GPa) } \\
\mathbf{3 0 0 K} / \mathbf{4 . 2 K}\end{array}$ & $\begin{array}{c}\text { Poisson's } \\
\text { Ratio }\end{array}$ & $\begin{array}{c}\text { Integrated Thermal } \\
\text { Contraction }(\mathbf{m m} / \mathbf{m})\end{array}$ \\
\hline Coil & Coil & $10 / 10$ & 0.3 & $4.5(\mathrm{x}), 3.5(\mathrm{y})$ \\
\hline End Saddles & Bronze & $110 / 110$ & 0.3 & 3.97 \\
\hline Coil Inserts and Shims & G-10 & $14 / 14$ & 0.3 & 2.75 \\
\hline Main and End Plates & 316 Steel & $210 / 225$ & 0.3 & 3.04 \\
\hline Side Pusher & 316 Steel & $210 / 225$ & 0.3 & 3.04 \\
\hline Side Bolts & Aluminum & $70 / 82$ & 0.3 & 4.24 \\
\hline Main bolts and End Bullets & 316 Steel & $210 / 225$ & 0.3 & 3.04 \\
\hline Washers on End Bolts & Invar & $140 / 140$ & 0.3 & 0.38 \\
\hline
\end{tabular}

Two separate 2D analyses were performed simulating preload, cool-down and excitation. The first was an analysis of the magnet cross-section, the second was on the coil plane. TABLE 1 shows the material properties used in these models. FIG. 4 shows the model of the cross-section and the equivalent stress in the coil at $17 \mathrm{kA}$ (the stresses in the other stages were significantly lower). The main bolt preloads are shown in the first column of TABLE 2. The upper bolt load is a factor 2 lower than the lower bolt load in order to minimize stress concentration at the edges of the coil caused by bending of the main plate. This bending occurs due to a small clearance between the surface of the main plate and the side pusher in the region of the upper bolt. The results of the second FE analysis are shown in TABLE 2 (preload) and in FIG. 5 (strain and stress in X-direction).
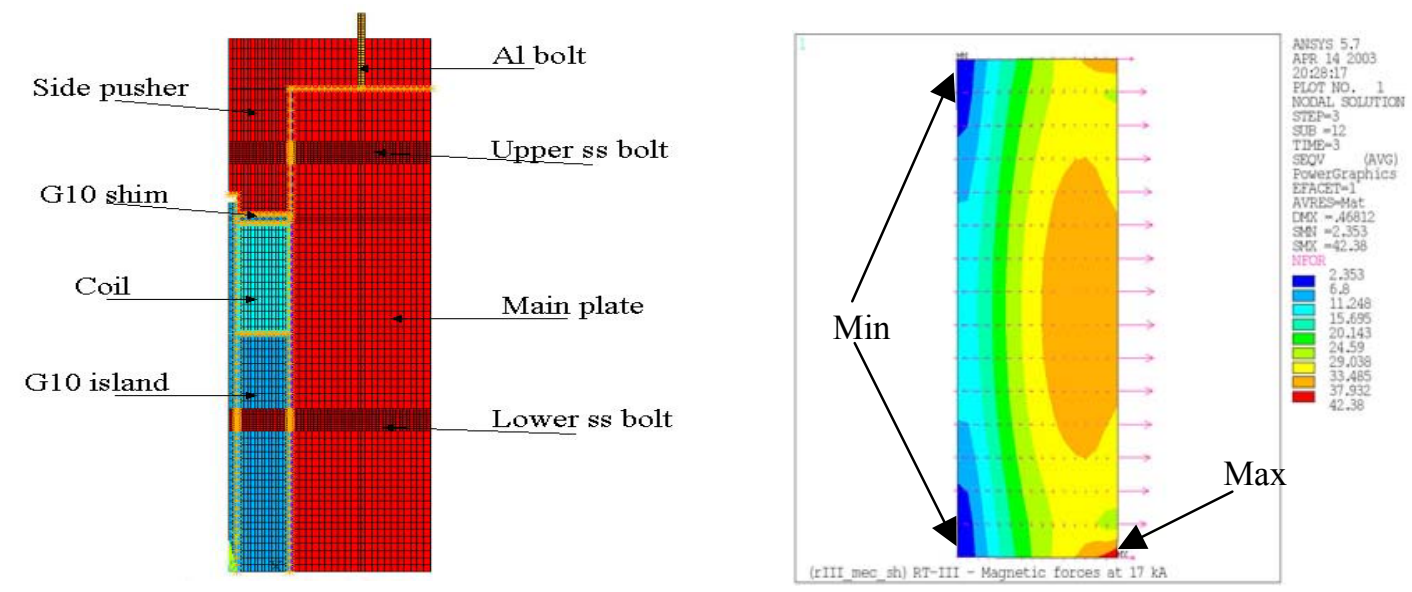

FIGURE 4. FE model of the cross-section and Von-Misses stresses at $17 \mathrm{kA}(\sigma \max =42 \mathrm{MPa})$

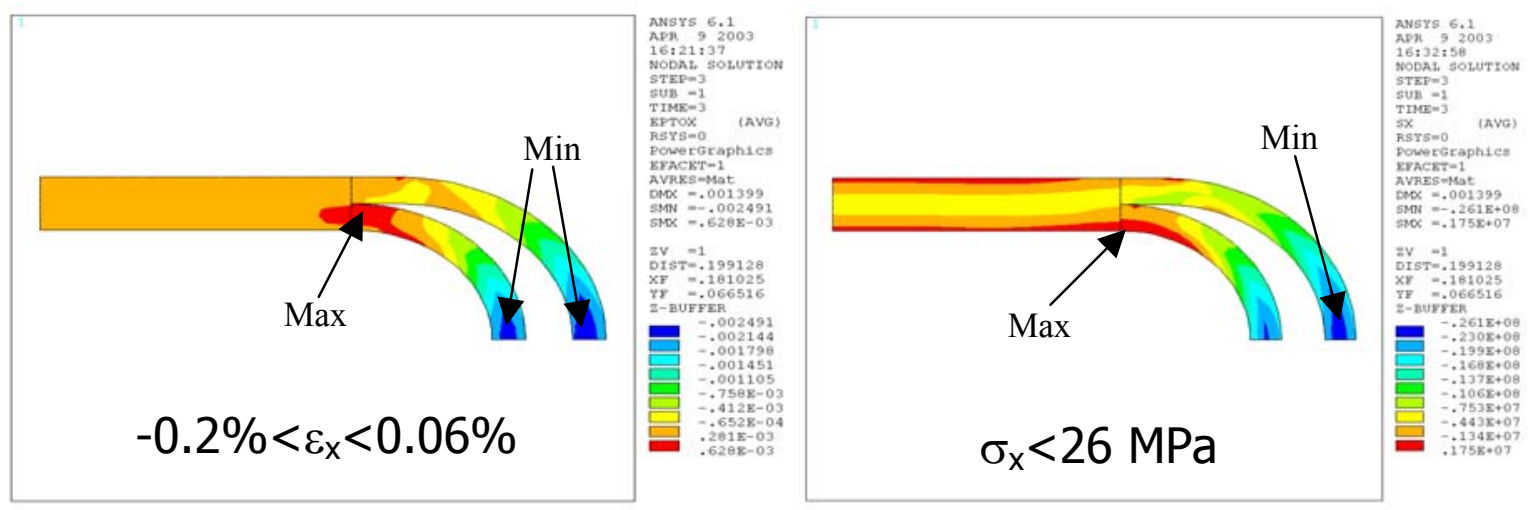

FIGURE 5. Coil strains and stresses (x-direction) 
TABLE 2. FEA results and comparison with measured loads.

\begin{tabular}{|c|c|c|c|c|c|c|}
\hline Bolt & $\begin{array}{c}\text { FEA } \\
(\mathbf{3 0 0 K})\end{array}$ & $\begin{array}{c}\text { Pre-Load } \\
\text { Test (300K) }\end{array}$ & $\begin{array}{c}\text { Cool-down } \\
(\mathbf{4 . 2} \text { K) FEA }\end{array}$ & $\begin{array}{c}\text { Cool-down } \\
(\mathbf{4 . 2 K}) \text { Test }\end{array}$ & $\begin{array}{c}\text { Excitation @ } \\
\text { 10 kA FEA }\end{array}$ & $\begin{array}{c}\text { Excitation @ } \\
\text { 10kA Test }\end{array}$ \\
\hline End Bullet 1 & 14560 & & 12209 & & 13668 & \\
\hline End Bullet 2 & 13103 & 9525 & 9891 & 4417 & 11438 & 4417 \\
\hline Side Bolt 1 & 3828 & & 655 & & 762 & \\
\hline Side Bolt 2 & 12218 & & 9578 & & 9877 & \\
\hline Side Bolt 3 & 11806 & 11542 & 9754 & 7548 & 10109 & 7255 \\
\hline Side Bolt 4 & 12909 & 11369 & 11599 & 9218 & 11660 & 8672 \\
\hline Side Bolt 5 & 3757 & & 3188 & & 2637 & \\
\hline Side Bolt 6 & 3763 & & 3612 & & 2501 & \\
\hline Side Bolt 7 & 3890 & & 3920 & & 2565 & \\
\hline Side Bolt 8 & 3932 & 4309 & 4017 & 3738 & 2627 & 3391 \\
\hline Main Bolt-outer & 10150 & 8455 & 276 & 0 & 15266 & 11650 \\
\hline
\end{tabular}

\section{HFDB-03 FABRICATION IMPROVEMENTS}

Based on the experience gained during the fabrication of HFDB-02, some steps of the fabrication process were modified. As mentioned earlier, a gap was introduced between the innermost turn of the cable and the core of the reaction spool (FIG. 6 left). Brass strips, 50$\mu \mathrm{m}$ thick, were used instead of wires for some voltage taps (FIG. 6 right). An L-shaped tool was used during fabrication to provide support to the cables in all stages of fabrication. This eliminated a problem that had occurred during HFDB-02 fabrication wherein the outermost turns had lifted up during the instrumentation. Additional mechanical instrumentation was also added by means of 8 instrumented end bullets ( 4 end bolts were instrumented in HFDB-02) and capacitance gages in the straight section of the coils to record coil stresses directly. The side instrumented bolts were redistributed such that they corresponded to the locations of peak load changes predicted by the finite element analysis.

Production tests were performed during magnet assembly to confirm that the preload targets were reached. The results are summarized in TABLE 2. The end bullet loads were about 30\% lower than the target values while the side loads were at the target levels and the main bolt loads were lower by about $20 \%$. The target loads in the main bolts and end bullets were not reached because of some bending that was observed in these bolts. The loading procedure was stopped when either of the strain gages mounted on these bolts or bullets reached the target value. All details regarding the fabrication of HFDB-03 may be found in [4].
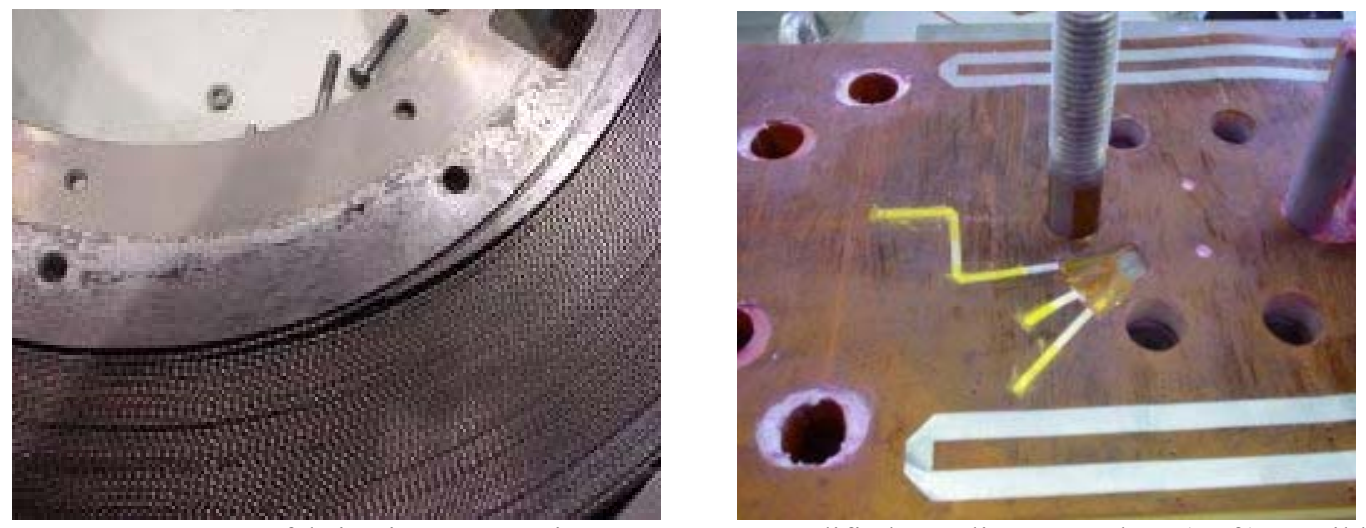

FIGURE 6. HFDB-03 fabrication process improvements: modified spooling procedure (Left), 2 mil brass strips for voltage taps (Right). 


\section{TEST RESULTS}

HFDB-03 was tested at Fermilab vertical magnet test facility [5] at $4.5 \mathrm{~K}$ and lower temperatures. A 30-m $\Omega$ dump resistance and quench heaters were used for protection.

The quench history is shown in FIG. 7. Initial training was performed at $4.5 \mathrm{~K}$ with 20 $\mathrm{A} / \mathrm{s}$ ramp rate. The first quench occurred at $8480 \mathrm{~A}$, followed by a series of 9 quenches at $10000 \mathrm{~A}(+/-300 \mathrm{~A})$. This current is significantly below the estimated short sample limit of $16530 \mathrm{~A}$ [4]. Subsequent ramp-rate studies (from 4 to $500 \mathrm{~A} / \mathrm{s}$ ) gave quench current values between 10233 and $10984 \mathrm{~A}$. In order to check if the ramp-rate studies had trained the magnet four more quenches at $20 \mathrm{~A} / \mathrm{s}$ were performed and the quench current, surprisingly, decreased below $10000 \mathrm{~A}$. Some more ramps at rates from 20 to $500 \mathrm{~A} / \mathrm{s}$ gave scattered quench currents between 9444 and $11020 \mathrm{~A}$.

Some spontaneous quenches at low current (minimum at 6289 A) occurred during the heater studies performed between quench 29 and 36. Fast ramps were subsequently studied and several of them were anticipated by an up-and-down cycle (for instance $0,10000,0 \mathrm{~A}$ ). These ramps are shown in FIG. 7 by open marks.

Several quenches at $20 \mathrm{~A} / \mathrm{s}$ were performed while the magnet temperature was lowered to $2.2 \mathrm{~K}$. They didn't show any significant effect of the temperature on the quench current. A final series of fast ramps were performed during magnet warm-up to $4.5 \mathrm{~K}$ achieving the highest quench current at $12590 \mathrm{~A}$ (76\% of the short sample limit). This result was obtained at $300 \mathrm{~A} / \mathrm{s}$ and the sensors glued to the coil edges recorded temperatures in the range from 6 to $7 \mathrm{~K}$ during the ramp.

Almost all quenches started from the same location: in the innermost turn of the top coil (on the top during magnet fabrication) close to the transition from the straight section to the lead end. The quench propagation was always very fast (for instance one third of a coil was normal after $20 \mathrm{~ms}$ in a typical quench at $10000 \mathrm{~A}$ ) and cannot be explained by simple longitudinal or transverse propagation.

The spot heaters were used to slowly heat the coil in a small region, while recording the temperature on an adjacent thermometer, allowing for a measurement of the temperature margin at fixed currents. Measurements were performed at 5, 7, 9 and $11 \mathrm{kA}$. The results of this test on the top coil were very similar to those of HFDB-02 showing that the tested section of cable was close to the short sample limit [6]. The same test on a

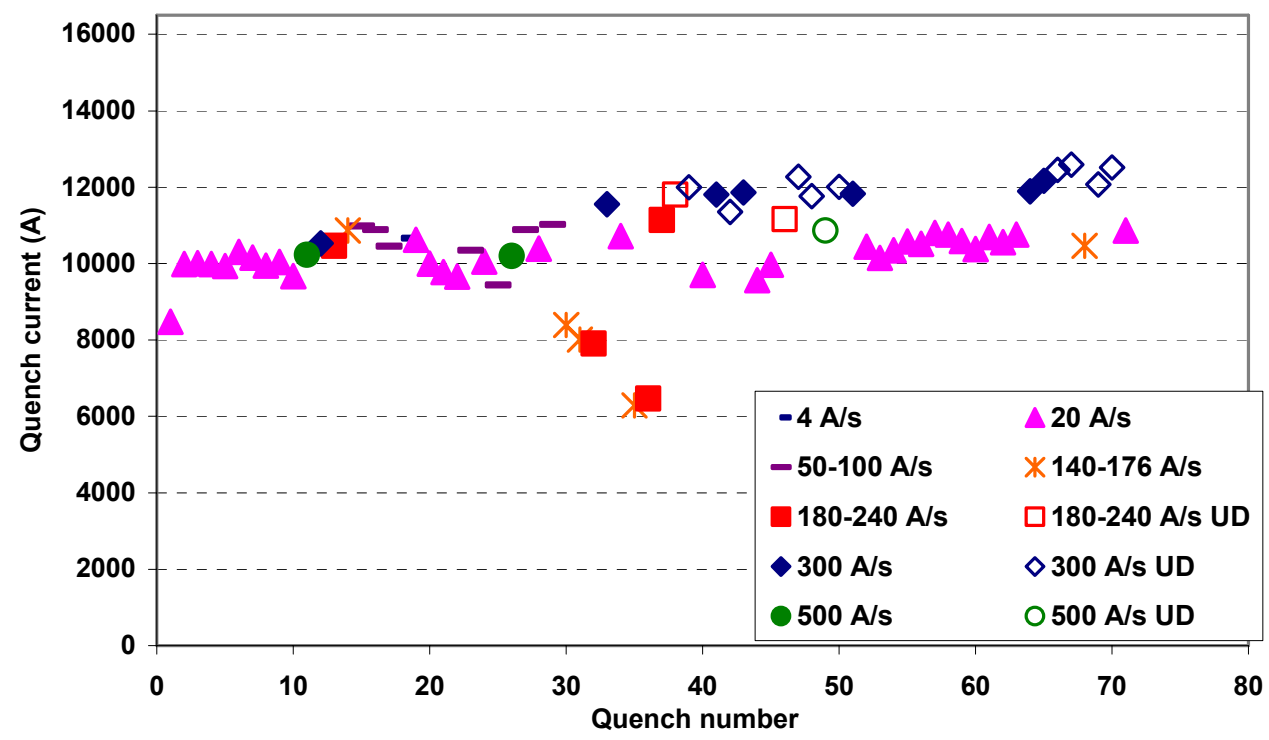

FIGURE 7. Quench history of HFDB-03. The short sample limit is at the top edge of the graph. Open marks indicate quench anticipated by an up-and-down cycle (UD). 
section of the bottom coil gave varying results (approximately from 0 to $10 \%$ degradation) and will be repeated in the second cold test.

The resistance of the lead splice was 0.3 and $0.2 \mathrm{n} \Omega$ in the bottom and top coil respectively, and $0.65 \mathrm{n} \Omega$ in both the splices to the NbTi layer-junction cable.

The predicted and measured bolt loads are shown in TABLE 2 after pre-stressing, at $4.2 \mathrm{~K}$ and at $10 \mathrm{kA}$. The instrumented side-bolts and end-bullets recorded a loss of load during cooldown higher than expected. During excitation the side-bolts showed a small loss, instead of the expected small gain, while the end bullets didn't record any load change. The instrumented main bolts lost all pre-stress during cooldown. FE analyses were repeated after tests in order to understand the cause of the discrepancies and a better agreement was found using higher values of the thermal contraction for G10 than the one reported in TABLE 1.
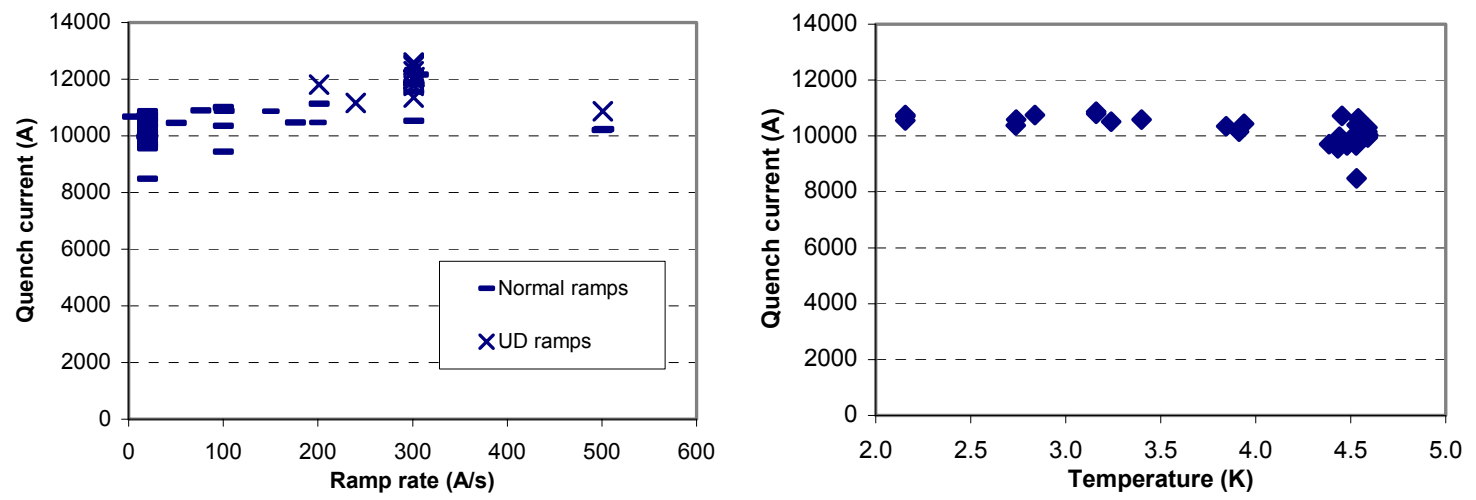

FIGURE 8. Quench current versus ramp rate (dI/dt) LEFT, and versus bath temperature (at $20 \mathrm{~A} / \mathrm{s}$ ) RIGHT.

A plot of quench current versus ramp rate is shown in FIG. 8 (the quenches occurred during spot heater study have been omitted). There is a large scattering of the results but a clear pattern is visible: there is a random behavior within a range of about $2000 \mathrm{~A}$ at any ramp rate and a tendency to increase up to $300 \mathrm{~A} / \mathrm{s}$ and to decrease at $500 \mathrm{~A} / \mathrm{s}$. This behavior could be caused by a 'resistive heating', but this hypothesis was falsified by a test during which the magnet remained at 11000 A for several minutes without quenching. Another possible explanation is a non-uniform distribution of the current in the strands, caused by boundary induced coupling currents and/or at the splices, supported by very large values of the inter-strand contact resistance measured on samples extracted from HFDB-02 [7]. Faster ramps should achieve a more uniform distribution than slower ramps allowing reaching higher quench currents. On the other side, at high ramps (i.e. $500 \mathrm{~A} / \mathrm{s}$ ) the AC loss increasing the coil temperature reduces the maximum current achievable. The trade-off determines the ramp that allows reaching the maximum current. This hypothesis is supported by the fact that ramps anticipated by up-and-down cycles gave on average better results.

FIG. 8 shows that the quench current at $20 \mathrm{~A} / \mathrm{s}$ ramp-rate is almost independent of the magnet temperature. This suggests a mechanical problem to be the cause of the limited performance. This hypothesis is supported by the lack of pre-stress in the direction of the main bolts after cooldown, but can hardly explain the ramp-rate dependence.

Several voltage spikes, with amplitudes up to $200 \mathrm{mV}$ and time extension up to $10 \mathrm{~ms}$, were recorder during almost all ramps. They can be attributed to micro-displacements of the conductor or to flux jumps [8].

The location where the quench started coincides with the point of highest tension in a 
non-supported coil (FIG. 2). The lack of load increment on the end-bullets indicates that part of the ends is not supported. These two factors indicates that an excessive strain, due a lack of complete support of the ends, could be the cause of the limited performance of this magnet. The ramp rate dependence could be explained, as mentioned earlier, by un-even current distribution among the strands. The quench current, under this hypothesis, should increase at lower temperature, but this increment should be opposed by the quadratic growth of forces (and strain) versus current and the scattering of the results may hide small differences.

\section{CONCLUSIONS}

HFDB-03 a racetrack magnet wound with pre-reacted $\mathrm{Nb}_{3} \mathrm{Sn}$ cable was fabricated and tested at Fermilab. Some modifications, with respect to the design and fabrication of HFDB-02, have been implemented. A first cold test with minimum pre-stress has been performed. The maximum current reached was 12590 A corresponding to $76 \%$ of the short sample limit. The ramp rate dependence had a peak at $300 \mathrm{~A} / \mathrm{s}$ and there was no significant change of the quench current versus temperature. Measurement of the temperature margin in a spot of the innermost turn of the top coil didn't show any degradation.

The strain gauges on end-bullets didn't record any load increment during magnet excitation. A high strain of the conductor, due to the action of the Lorentz forces on not well supports coil ends, could be the cause of the limited performance.

A second test is planned with higher pre-stress.

\section{ACKNOWLEDGMENTS}

This work is supported by the US Department of Energy.

\section{REFERENCES}

1. G. Ambrosio et al., "R\&D for a Single-Layer $\mathrm{Nb}_{3}$ SnCommon Coil Dipole using the React-and-Wind Fabrication Technique", in IEEE Transactions on Applied Superconductivity, vol. 12, no. 1, pp. 39-42.

2. G. Ambrosio, et al.,"Fabrication and Test of a Racetrack Magnet Using Pre-Reacted $\mathrm{Nb}_{3} \mathrm{Sn} \mathrm{Cable"} \mathrm{in}$ IEEE Trans. Appl. Supercond., vol. 13, no. 2, pp. 1284-1287.

3. G. Ambrosio, N. Andreev, S. Bhashyam, I. Novitski, "HFDB-02 $2^{\text {nd }}$ Racetrack Production Report", Fermilab Technical Division report TD-02-032*.

4. G. Ambrosio, N. Andreev, S. Bhashyam, "HFDB-03 $3{ }^{\text {rd }}$ Racetrack Production Report", Fermilab Technical Division report TD-03-018*.

5. T.J. Peterson, et al., "A 1400 liter $1.8 \mathrm{~K}$ test facility” in Advances in Cryogenic Engineering 43A, pp. 541-548 (1998).

6. G. Ambrosio, P.Bauer, S.Feher, A.Godeke, L.Imbasciati, J.Tompkins "Measurement of the Temperature Margin in HFDB-02", Fermilab Technical Division report TD-02-024*

7. G. Ambrosio, E. Barzi, L. Elementi, A.V. Zlobin, "Measurement of inter-strand contact resistance in epoxy impregnated Nb3Sn Rutherford cables", presented at this conference (M3-G-02).

8. L. Chiesa, et al., "Performance comparison of Nb3Sn magnets at LBNL" " in IEEE Trans. Appl. Supercond., vol. 13, no. 2, pp. 1254-1257.

* Available on line at: http://www-td.fnal.gov/info/td library.html 